\title{
Note from the editors: Open access and sound science for rapid public health action
}

Eurosurveillance editorial team ${ }^{1}$

1. European Centre for Disease Prevention and Control (ECDC), Stockholm, Sweden

Correspondence: Eurosurveillance editorial team (eurosurveillance@ecdc.europa.eu)

Citation style for this article:

Eurosurveillance editorial team. Note from the editors: Open access and sound science for rapid public health action. Euro Surveill. 2019;24(2):pii=1901101.

https://doi.org/10.2807/1560-7917.ES.2019.24.2.1901101

Article published on 10 Jan 2019

In 2018, public health experts and scientists concerned with the epidemiology and control of infectious diseases in Europe continued to be busy handling outbreaks and (re)-emerging infectious diseases; however, in contrast to recent years, there was no single overriding public health event that caught global attention. Nonetheless, there were developments that kept experts alert and that we editors followed with great interest.

Artificial intelligence (Al) continued to gain momentum and was widely acknowledged as an evolution that will fundamentally affect our societies and the ways that we generate knowledge. In the field of infectious disease, concrete examples of self-learning applications with some freedom of decision-making are still scarce. This was one of the messages from the 2018 Eurosurveillance seminar at ESCAIDE, Artificial intelligence (AI) in epidemiology: a reality in 2018? Discussions at this event also brought forward that now is a good time to tackle basic questions on ethics, infrastructure and training needs for epidemiologists and (public health) microbiologists related to Al. Such questions need to be addressed in an interdisciplinary collaboration with computer scientists, ethicists, social scientists and many others. We at Eurosurveillance will keep an eye on further developments on this topic, and we welcome the submission of articles in which authors share concrete examples of applied $\mathrm{Al}$ in public health and infectious disease epidemiology and surveillance.

The editorial team continuously strives to increase transparency of reporting, as well as the quality of articles published in Eurosurveillance. In 2018, we fine-tuned the authors' instructions for outbreak articles. New instructions for surveillance articles were developed in collaboration with the editorial board and will be posted online soon. They should streamline and thus improve the presentation of surveillance data to boost the impact of this important feature of Eurosurveillance. From the beginning of 2019, Eurosurveillance has mandated the depositing of sequence data in open access public repositories ahead of submission, as well as the inclusion of ethical statements in regular articles. The journal's editorial policy has endorsed the use of several reporting guidelines for many years, and starting in 2019 we will mandate that new submissions include checklists for certain article types: the PRISMA checklist for systematic reviews, the CHEERS checklist for health economic studies and the CONSORT checklist for clinical trials. While we strongly recommend that authors follow STROBE guidelines for the reporting of observational studies, we do not mandate the submission of STROBE checklists at present.

Support from reviewers, editorial board members, colleagues, our publisher the European Centre for Disease Prevention and Control (ECDC) and ECDC's Director, as well as many others, has been invaluable in 2018. We are immensely grateful for the strategic and scientific advice, moral and day-to-day support and sustained funding that allows us to publish and disseminate information we deem to be sound science capable of informing public health decision-making.

Peer-review offers a great opportunity to engage experts in improving the quality of scientific work by adding new perspectives and insight, when reviews are conducted thoroughly and respectfully. We are aware that peer-review has been criticised as ineffective and biased by parts of the scientific community. Still, we believe it is a learning opportunity for both those giving feedback and those receiving it, and we editors who moderate this process profit considerably from everyone who gives their time and shares their expertise to guide us and authors. To support reviewers in their assessment of the completeness and comprehensiveness of manuscripts, we will send the 
filled-in checklists submitted by authors together with the manuscripts for review, and we hope that reviewers will find this useful.

Our means to express our gratitude for support are limited. Traditionally, we publish a list with the names of all peer-reviewers at the beginning of each year to thank them. In 2018, nearly 500 individuals supported us with formal reviews [1], and we would like to extend our thanks to all those who may remain unnamed but who nonetheless provided helpful advice. In order to further recognise our peer-reviewers, we will send certificates to experts who completed more than one review in 2018. We are also happy to confirm reviewing activities on recognised platforms such as Publons [2], upon request. Please do not hesitate to contact the editorial office if you need a certificate or confirmation in another way.

In 2018, we published 182 articles (52 Rapid communications, 115 regular articles, 15 other items such as editorials, letters and meeting reports). The 2018 acceptance rate of $26 \%$ was similar to previous years and, while we received submissions from around the world, the selection of articles was guided by relevance for public health in Europe and thus the vast majority of published articles were from Europe. Our Rapid communications, published within 2 to 3 weeks of submission, reported on ongoing or emerging threats to support rapid public health action, as we have done for many years. We covered events such as the nationwide outbreak of Salmonella Agona associated with internationally distributed infant milk products in France [3], the unusually early start of West Nile virus transmission season in Europe [4] and the upsurge of different enteroviruses associated with severe illness in some countries [5-7], and also published timely communications about influenza vaccine effectiveness [8-11].

We published several topical and special issues that collated data and evidence to support communication on specific topics, in some instances for particular health days or weeks. These issues covered important aspects of vaccination, HIV/AIDS and antimicrobial resistance, topics that continue to be high on our agenda. We hope that the articles we have publishedsuch as those on the results from the 2016 to 2017 European point prevalence survey on antimicrobial use and healthcare-associated infections in acute and long-term care facilities [12] - serve as quality evidence to support effective public health decision-making.

The 2018 special issues resulting from dedicated calls for papers were 'Screening and prevention of infectious diseases in newly arrived migrants in Europe' and, in December, the first part of a special issue demonstrating how novel approaches in molecular diagnostics support traditional epidemiology and public heath decision-making, the second part of which will follow at the end of January 2019. In February, we will launch a call for papers on the use of point of impact testing
(POIT)/point of care testing (POCT) and self-testing in surveillance and epidemiology.

Various metrics showed that Eurosurveillance remained among the leading journals in its field in 2018. The journal's most recent impact factor, released in mid2018, was 7.1, ranking Eurosurveillance fifth in the category Infectious Diseases. The journal remained in the first quartile (for all categories listed) in the SCImago Journal Rank and Google Scholar metrics continued to be equally favourable. The Scopus-based CiteScore for Eurosurveillance improved from 3.7 to 5.0 and the CiteScore Percentile went up to $98 \%$, corresponding to rank six among 478 journals in the category Medicine: Public Health, Environmental and Occupational Health.

Of relevance to our authors, reviewers and subscribers, 2018 also brought the new General Data Protection Regulation (GDPR) for Europe [13]. The GDPR caused concern for some, but reassured others that their privacy will be better protected. Eurosurveillance editors have long been sensitive to the need to protect the privacy of individuals and most GDPR requirements were already being followed before it came into effect. In light of the growing number of funders requesting instant open access for (community)-funded science, we would like to remind our authors and readers that Eurosurveillance is a well-recognised, open-access journal that provides a European platform for health professionals to share quality scientific findings in infectious disease epidemiology, prevention and control.

At Eurosurveillance we nurture close ties with our collaborators, authors, board members and colleagues at ECDC, and we enjoy this part of our work. It helps us develop the journal and identify topics of interest. Moreover, we gain insight into public health needs, which is crucial for our aim to be the authoritative and representative public health voice of the communicable disease community in Europe and beyond. Towards this objective, we aspire to provide facts and guidance for health professionals and decision-makers, to facilitate the implementation of effective prevention and control measures, and to support the preparedness and response to health threats in Europe through the rapid dissemination of high-quality, authoritative scientific information on relevant outbreaks or emergency situations. We look forward to fulfilling our aims in 2019, jointly with our contributors and many other supporters, and we wish all of them a productive and good year!

\section{References}

1. Eurosurveillance editorial team. Eurosurveillance reviewers in 2018. Euro Surveill. 2019;24(2):1901102. https://doi. org/10.2807/1560-7917.ES.2019.24.2.1901102

2. publons.com. London: Publons. [Accessed 10 Jan 2018]. Available from: https://publons.com/about/home/

3. Jourdan-da Silva N, Fabre L, Robinson E, Fournet N, Nisavanh $A$, Bruyand $M$, et al. Ongoing nationwide outbreak of 
Salmonella Agona associated with internationally distributed infant milk products, France, December 2017. Euro Surveill. 2018;23(2):17-00852. https://doi.org/10.2807/1560-7917. ES.2018.23.2.17-00852

4. Haussig JM, Young JJ, Gossner CM, Mezei E, Bella A, Sirbu A et al. Early start of the West Nile fever transmission season 2018 in Europe. Euro Surveill. 2018;23(32):1800428. https:// doi.org/10.2807/1560-7917.ES.2018.23.32.1800428 PMID: 30107869

5. Cottrell S, Moore C, Perry M, Hilvers E, Williams C, Shankar AG. Prospective enterovirus D68 (EV-D68) surveillance from September 2015 to November 2018 indicates a current wave of activity in Wales. Euro Surveill. 2018;23(46):1800578. https:// doi.org/10.2807/1560-7917.ES.2018.23.46.1800578 PMID: 30458915

6. Nhan LNT, Hong NTT, Nhu LNT, Nguyet LA, Ny NTH, Thanh TT, et al. Severe enterovirus A71 associated hand, foot and mouth disease, Vietnam, 2018: preliminary report of an impending outbreak. Euro Surveill. 2018;23(46):1800590. https:// doi.org/10.2807/1560-7917.ES.2018.23.46.1800590 PMID: 30458911

7. Broberg EK, Simone B, Jansa JThe Eu/Eea Member State Contributors. Upsurge in echovirus 30 detections in five EU/EEA countries, April to September, 2018. Euro Surveill. 2018;23(44):1800537. https://doi.org/10.2807/1560-7917. ES.2018.23.44.1800537 PMID: 30401013

8. Rondy M, Kissling E, Emborg HD, Gherasim A, Pebody R, Trebbien R, et al. I-MOVE/I-MOVE+ group. Interim 2017/18 influenza seasonal vaccine effectiveness: combined results from five European studies. Euro Surveill. 2018;23(9):18-00086. https://doi.org/10.2807/1560-7917. ES.2018.23.9.18-00086

9. Skowronski DM, Chambers C, De Serres G, Dickinson JA, Winter AL, Hickman R, et al. Early season co-circulation of influenza $A\left(\mathrm{H}_{3} \mathrm{~N}_{2}\right)$ and $B$ (Yamagata): interim estimates of 2017/18 vaccine effectiveness, Canada, January 2018. Euro Surveill. 2018;23(5):18-00035. https://doi.org/10.2807/15607917.ES.2018.23.5.18-00035

10. Chiu SS, Kwan MYW, Feng S, Wong JSC, Leung CW, Chan ELY, et al. Interim estimate of influenza vaccine effectiveness in hospitalised children, Hong Kong, 2017/18. Euro Surveill. 2018;23(8):18-00062. https://doi.org/10.2807/1560-7917. ES.2018.23.8.18-00062

11. Castilla J, Navascués A, Casado I, Pérez-García A, Aguinaga A, Ezpeleta G, et al. Interim effectiveness of trivalent influenza vaccine in a season dominated by lineage mismatched influenza B, northern Spain, 2017/18. Euro Surveill. 2018;23(7):18-00057. https://doi.org/10.2807/1560-7917. ES.2018.23.7.18-00057

12. Eurosurveillance. Special edition: Antimicrobial use and prevalence of healthcare-associated infections in acute and long-term care facilities. European Centre for Disease Prevention and Control (ECDC): Stockholm; 2018. Available from: https://www.eurosurveillance.org/upload/site-assets/ imgs/Special_Issue_EAAD-web.pdf

13. Regulation (EU) $2016 / 679$ of the European Parliament and of the Council of 27 April 2016 on the protection of natural persons with regard to the processing of personal data and on the free movement of such data, and repealing Directive 95/46/EC (General Data Protection Regulation). Official Journal of the European Union, Vol. L119 (4 May 2016), pp. 1-88.

\section{License and copyright}

This is an open-access article distributed under the terms of the Creative Commons Attribution (CC BY 4.0) Licence. You may share and adapt the material, but must give appropriate credit to the source, provide a link to the licence, and indicate if changes were made.

This article is copyright of the authors, 2019. 